\title{
How to Choose the Right Valve Prosthesis for My Patient?
}

\author{
Roney Orismar Sampaio \\ Instituto do Coração do Hospital das Clínicas da Faculdade de Medicina da Universidade de São Paulo, São Paulo, SP - Brazil \\ Short Editorial related to the article: Comparison of Biological and Mechanical Prostheses for Heart Valve Surgery: A Systematic Review of \\ Randomized Controlled Trials
}

The manuscript: "Comparison of Biological and Mechanical Prostheses for Heart Valve Surgery: Systematic Review of Randomized Controlled Trials" ${ }^{1}$ addresses a controversial issue. The authors conducted a meta-analysis of randomized trials involving long-term follow-up of patients requiring cardiac valve replacement revealing similar mortality among patients who underwent implantation of biological prostheses and those who underwent implantation of mechanical prosthesis. There were no significant differences in the risk of thromboembolism and endocarditis. However, the risk of bleeding was approximately one-third lower among patients treated with biological prostheses than those treated with mechanical prostheses. In contrast, the need for reoperation among patients treated with bioprostheses was at least three times greater than that of patients treated with mechanical prostheses.

The authors selected "randomized" trials to avoid evaluation bias. The trial is interesting, as it seeks to be faithful to randomized evaluations, which are very unusual in the literature on valve diseases, especially at the time when the trials were conducted.

The choice of the valve prosthesis that is most appropriate for our patients should consider classic factors such as age (young adults: most likely, mechanical prosthesis/elderly: biological prosthesis), sex (women of childbearing age: most likely, biological prosthesis), number of previous cardiac surgeries (two or more surgeries: mechanical prostheses are the preferred ones), need for permanent anticoagulation (mechanical prostheses), social and educational factors (difficulty in accepting or controlling anticoagulation and/or contraindication to anticoagulation: biological prostheses), and, more importantly, the patient's preference should be respected. ${ }^{2}$

Considering the age factor alone, the guidelines on valve diseases have recommended choosing mechanical prostheses for younger patients, that is, under the age of 50 (AHA/ACC/ESC) and biological prostheses for patients older than 65-70. ${ }^{3,4}$ However, the best prosthesis for those between 50 and 70 years of age remains controversial. ${ }^{3-5}$

\section{Keywords}

Heart Valve Prosthesis; Bioprosthesis, Metal on Metal Joint Prostheses; Heart Valve Prosthesis Implantation/trends.

Mailing Address: Roney Orismar Sampaio •

Av. Dr. Eneas de Carvalho Aguiar, 44, Bloco 2, Andar AB, Unidade de Cardiopatias Valvares. Postal Code 05654-040, Cerqueira Cesar, São Paulo, SP - Brasil E-mail: orismar@cardiol.br, sampaioroney@yahoo.com.br

DOI: $10.5935 / a b c .20190026$
Recent evaluations have demonstrated a potentially longer durability of the most modern biological prostheses and a worldwide tendency to choose this prosthesis for increasingly younger. From the decade of 1990 to 2013, there was a three to four-fold increase in the implantation of biological prostheses in both aortic and mitral positions. ${ }^{6}$ New medical techniques, such as the possibility of implanting a prosthesis in another prosthesis (valve-in-valve), ${ }^{7}$ has also been promising, to avoid the use of mechanical prostheses and mandatory anticoagulation and their known risks, that is, bleeding and/or thromboembolic events.

The study by Takeshi et al. ${ }^{1}$ found that "both prostheses have similar late mortality." However, we know that these findings may have occurred due to evaluation bias due to inadequate follow-up time in most randomized or observational trials. ${ }^{8,9}$ Besides, valve prostheses evaluated in these studies are mostly outdated or even not available for purchase. The information is "historical," but continuous evaluation is still required to identify the actual durability of the prostheses, which vary greatly. The structural deterioration of biological prostheses correlates with the age of implant, so in 15 years' time, $50 \%$ of the prostheses implanted at the age of 20 will have structural deterioration, dropping to $30 \%$ if implanted at 40 and $10 \%$ if after $70 .^{3}$

The relevance of this study is that it calls attention to an underdiscussed topic. Biological prostheses with the latest technology may last longer, compromising the main reason for using mechanical prostheses, which is to prevent further cardiac surgeries. However, the same can occur with mechanical prostheses with a better technological profile, thus reducing the need for anticoagulation with high INR values. It is also known that compliant patients, with excellent anticoagulation monitoring, have reduced bleeding or thromboembolic events.

Endoprostheses implanted by catheter have contributed to changes in this scenario, and we believe that the trend of implanting biological prostheses in increasingly younger patients should become usual in the near future.

In conclusion, it seems reasonable to admit the choice of biological prostheses in patients who do not need permanent anticoagulation, aged over 60-65 years, for women who wish to get pregnant and patients with difficulty in monitoring or with contraindication to anticoagulation. On the other hand, mechanical prostheses should be reserved for younger patients, chronic users of anticoagulants and patients with multiple surgeries. Note that the final decision should be the patient's, after detailed explanation of the benefits and drawbacks of each prosthesis, by their clinical cardiologist and surgeon. 


\section{Short Editorial}

\section{References}

1. Kiyose AT, Suzumura EA, Laranjeira L, Buehler AM, Espirito Santo JA, Berwanger $\mathrm{O}$, et al. Comparação de próteses biológicas e mecânicas para cirurgia de valvula cardíaca:revisão sistemática de estudos controlados randomizados. Arq Bras Cardiol. 2019; 112(3):292-301.

2. Tarasoutchi F, Montera MW, Ramos AIO, Sampaio RO, Rosa Vee, Accorsi TAD, etal. Atualização das Diretrizes Brasileiras de Valvopatias: abordagem das lesões anatomicamente importantes. Arq Bras Cardiol 2017: 109(6 supl 2):1-34.

3. Nishimura RA, Otto CM, Bonow RO, Carabello BA, Erwin JP 3rd, Fleister LA, et al. 2017 AHA/ACC Focused Update of the 2014 AHA/ ACC Guideline for the Management of Patients With Valvular Heart Disease A Report of the American College of Cardiology/American Heart Association Task Force on Clinical Practice Guidelines. Circulation. 2017;135(25):e1159-e1195.

4. Baumgartner H, Falk V, Bax JJ, De Bonis M, Hamm C, Holm PJ, et al. 2017 ESC/EACTS Guidelines for the management of valvular heart disease The Task Force for the Management of Valvular Heart Disease of the European Society of Cardiology (ESC) and the European
Association for Cardio- Thoracic Surgery (EACTS). Eur Heart J. 2017;38(36):2739-91.

5. Head SJ, ÇelikM, Kappetein AP. Mechanical versus bioprosthetic aortic valve replacement. Eur Heart J. 2017; 38(28):2183-91

6. Goldstone AB, Chiu P, Baiocchi M, Lingala B, Patrick WL, FischbeinMP, Woo YJ. Mechanical or biologic prostheses for aortic-valve and mitral-valve replacement. N Engl J Med. 2017; 377(19):1847-57.

7. Sampaio RO, Paixão MR, Miranda TT, Veronese ET, Palma JHA, Tarasoutchi F. Combined mitral and aortic valvar bioprosthesis transcatheter transapical implant: first description in Brazil. Arq Bras Cardiol. 2017;109(5):491-4.

8. Chikwe J, Chiang YP, Egorova NN, Itagaki S, Adams DH. Survival and outcomes following bioprosthetic vs mechanical mitral valve replacement in patients aged 50 to 69 years. JAMA. 2015; 313(14):1435-42.

9. Hirji AS, Kolkailah AA, Ramirez-Del Val F, Lee J,McGurk S, Pelletier M, et al. Mechanical versus bioprosthetic aortic valve replacement in patients aged 50 years and younger. Ann Thorac Surg. 2018;106(4):1113-20. 